\title{
Microwave-Assisted Method for Simultaneous Hydrolysis and Extraction for Preparation of Geniposidic Acid from Eucommia ulmoides Bark Using Basic Imidazolide Ionic Liquid
}

\author{
Lili Li, ${ }^{1,2}$ Yupin Guo, ${ }^{3}$ Chunchao Zhao, ${ }^{1,2}$ Mengxia Wei, ${ }^{1,2}$ \\ Junling Liu, ${ }^{1,2}$ Yuangang Zu, ${ }^{1,2}$ Fei Wang, ${ }^{4}$ and Lei Yang ${ }^{1,2}$ \\ ${ }^{1}$ Key Laboratory of Forest Plant Ecology, Ministry of Education, Northeast Forestry University, Harbin 150040, China \\ ${ }^{2}$ State Engineering Laboratory for Bioresource Eco-Utilization, Northeast Forestry University, Harbin 150040, China \\ ${ }^{3}$ College of Animal Science and Technology, Hebei North University, Zhangjiakou 075000, China \\ ${ }^{4}$ Landscape Architecture College, Northeast Forestry University, Harbin 150040, China \\ Correspondence should be addressed to Lei Yang; yanglei@nefu.edu.cn
}

Received 2 February 2016; Revised 24 March 2016; Accepted 30 March 2016

Academic Editor: Dmitry Murzin

Copyright ( 2016 Lili Li et al. This is an open access article distributed under the Creative Commons Attribution License, which permits unrestricted use, distribution, and reproduction in any medium, provided the original work is properly cited.

\begin{abstract}
In order to hydrolyze geniposide and extract geniposidic acid, a novel microwave irradiation heating method for simultaneous hydrolysis and extraction for preparation of geniposidic acid from Eucommia ulmoides bark using basic imidazolide ionic liquid was developed in this work. Basic ionic liquid paired by imidazolide anion and 1-hexyl-3-methylimidazolium cation ([C6mim] Im) was used as a dual hydrolysis catalyst and extraction solvent in the proposed approach. The optimal concentration of [C6 mim] Im was $0.4 \mathrm{~mol} / \mathrm{L}$. And the independent parameters optimized by Box-Behnken design (BBD) based on single-factor tests were as follows: microwave irradiation time of $20 \mathrm{~min}$ at power of $415 \mathrm{~W}$ and liquid-solid ratio of $15 \mathrm{~mL} / \mathrm{g}$. Yield of geniposidic acid was increased to $3.41 \pm 0.17 \mu \mathrm{mol} / \mathrm{g}$. DM130 macroporous resin, after reaction, was selected to separate geniposidic acid from hydrolysate. The plant materials with different treatment were analyzed by scanning electron microscopy (SEM) and thermogravimetric analysis (TG). The analysis of SEM and TG further indicated that IMSHE is an efficient preparation method for geniposidic acid. It is reasonable to assume that the method and the dual hydrolysis catalyst and extraction solvent would offer an alternative for the preparation of some other kinds of bioactive substances from plant materials.
\end{abstract}

\section{Introduction}

Eucommia ulmoides, belonging to Eucommiaceae, is a unique kind of plant in China. The E. ulmoides bark has been used as tonic herbs for more than 2000 years, and now it is listed in Chinese Pharmacopoeia. Lee et al. [1] and Luo et al. [2] have used it for the treatment of obesity and hypertension. It is also used for strengthening tendons and bones [3], antioxidation, and protecting red blood cell $[4,5]$. Previous literatures $[6$, 7] have reported that some components from bark of $E$. ulmoides have antihypertensive effect by releasing vascular relaxing molecules such as nitric oxide and endotheliumderived hyperpolarizing factor from endothelium. Geniposidic acid, an iridoids compound from E. ulmoides barks, was proved to be the main antihypertensive component [8]. In addition, geniposidic acid has other pharmacological effects: treating hepatic disorders [9], antitumor and radioprotection [10], hypotensive effect [11], and antiatherosclerotic [12]. However, the existence of geniposidic acid in E. ulmoides bark is very low $(0.049 \%-0.130 \%)$ [13], which results in its high price.

Geniposide is another important component of $E$. ulmoides bark, which can be hydrolyzed by sodium hydroxide solution to produce geniposidic acid [14]. Steps needed for the preparation of geniposidic acid are as follows: (1) extraction of geniposide with appropriate concentration of organic solvent; (2) isolation of crude extracts (containing geniposide) from plant materials; (3) removing extraction solvent from crude extracts; (4) adding sodium hydroxide solution to the crude extracts and hydrolyzing geniposide to 


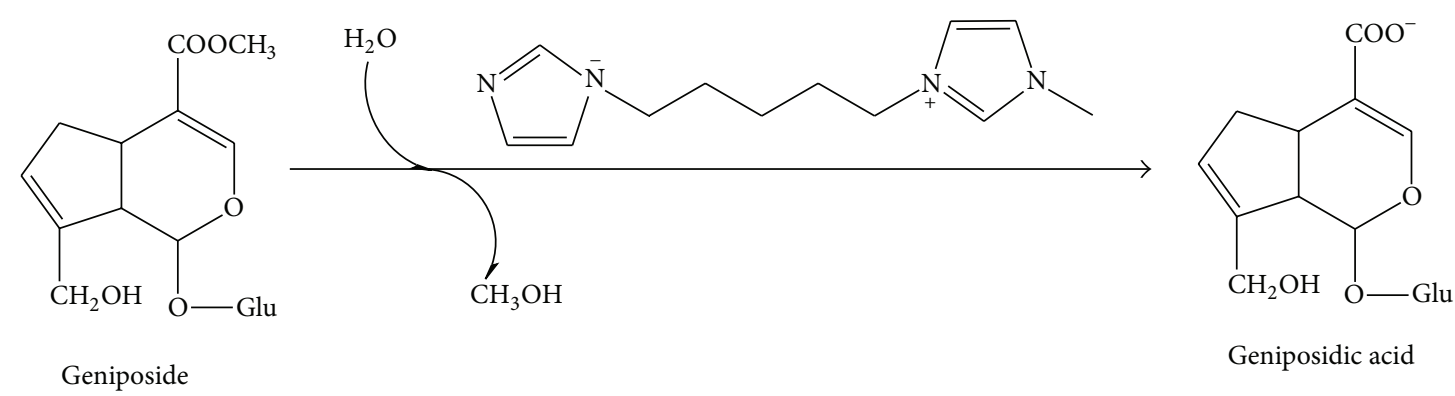

FIGURE 1: Hydrolysis mechanism of geniposide to form geniposidic acid.

geniposidic acid under the appropriate conditions. The above scheme has some limitations, such as requirement of tedious procedure, long hydrolysis time, high energy consumption, and harsh hydrolysis conditions. Therefore, development of simple, high-yielding, efficient, and environmentally-friendly approach using a new dual solvent-catalyst for the hydrolysis of geniposide is an important task.

Recently, some reports have demonstrated that ionic liquids can replace conventional volatile organic solvents because the ionic liquids possess unique chemical and physical characteristics in many fields [15-17]. Generally, ionic liquids were used for extracting various active constituents from plant materials including polyphenolic compounds [18] and lignans $[19,20]$ because ionic liquids can decompose cellulose of cell wall $[21,22]$, inducing releasing the intracellular bioactive constituents from plant cell walls. Furthermore, microwave irradiation has gained extensive attention in many fields as a high efficiency, energy conservation, and easy control energy source because the materials can be heated internally rapidly. Additionally, Liu et al. [23] and Chen et al. [24] have proved that microwave irradiation can dramatically improve the performance of ionic liquids because the ionic liquids have excellent microwave absorbing abilities. It is difficult to use conventional ionic liquids as catalysts in various chemical reactions due to the properties of low alkalinity [25]. Chen et al. [26] firstly reported that imidazolide basic ionic liquids with strong alkalinity have promising application prospects in replacement of traditional basic catalysts such as sodium hydroxide and Zawadzki et al. [27] used it as extraction solvent; hence it could be used as dual solvents-catalysts. They are flexible, nonvolatile, reusable, and immiscible with many organic solvents [27, 28]. So far, there is no research in the literature about preparing geniposidic acid by hydrolysis and simultaneous extraction using imidazolide basic ionic liquids.

In this paper, microwave-assisted method for simultaneous hydrolysis and extraction using basic imidazolide ionic liquid (IMSHE) was developed for preparation of geniposidic acid from E. ulmoides bark. The performance of 1-alkyl-3methylimidazolium imidazolide was compared with acetate radical and hydroxide radical anions in this paper. Five different cations with the same anion were also studied. And 1hexyl-3-methylimidazolium imidazolide ([C6mim] Im) was selected as the dual solvent-catalyst in IMSHE processes.
The hydrolysis mechanism is given in Figure 1. Various parameters of IMSHE were systematically studied including concentration of [C6mim] Im, microwave irradiation power and time, and dosage of solvent. After being treated with different processes, the plant materials were analyzed by scanning electron microscopy (SEM) and thermogravimetric analysis (TG).

\section{Materials and Methods}

2.1. Material and Chemicals. The bark of E. ulmoides gained from Tongrentang Ltd. (Harbin, Heilongjiang, China) was ground and then sieved $(150-250 \mu \mathrm{m})$. Geniposide and geniposidic acid references (98\% purity) were obtained from the Sigma Aldrich Co. Ltd. (Shanghai, China). Ionic liquids used in the present study including $[\mathrm{C} 4 \mathrm{mim}] \mathrm{OH},[\mathrm{C} 6 \mathrm{mim}] \mathrm{OH}$, [C8mim] OH, [C4mim] OAc, [C6mim] OAc, [C8mim]OAc, [C2mim]Im, [C4mim]Im, [C6mim]Im, [C8mim] Im, and [C10mim $] \mathrm{Im}\left([\mathrm{C} 2 \mathrm{mim}]^{+}\right.$is 1-ethyl-3-methylimidazolium positive ion, [C4mim $]^{+}$is 1-butyl-3-methylimidazolium positive ion, [C6mim $]^{+}$is 1-hexyl-3-methylimidazolium positive ion, $[\mathrm{C} 8 \mathrm{mim}]^{+}$is 1-octyl-3-methylimidazolium positive ion, $[\mathrm{Cl0mim}]^{+}$is 1-decyl-3-methylimidazolium positive ion, $\mathrm{OH}^{-}$is hydroxide radical negative ion, $\mathrm{OAc}^{-}$is acetate radical negative ion, and $\mathrm{Im}^{-}$is imidazolide radical negative ion) bought from Chengjie Chemical Co. Ltd. (Shanghai, China) and were used without any other treatment. Methanol, acetonitrile, and glacial acetic acid purchased from Thermo Fisher Scientific Inc. (Shanghai, China) for HPLC analysis were of chromatographic grade. Petroleum ether (boiling in the range of $60^{\circ} \mathrm{C}$ to $90^{\circ} \mathrm{C}$ ) and sodium hydroxide were purchased from Aladdin (Shanghai, China).

2.2. High Performance Liquid Chromatography Analysis. A high performance liquid chromatography (HPLC) system consisted of a 1525 model pump, a 717 plus model autosampler, and 2487 model ultraviolet detector (Waters Corporation, Milford Massachusetts, USA) which were employed for HPLC analyses. Chromatographic separation was performed on a Hypersil BDS C18 column $(4.6 \mathrm{~mm} \times 250 \mathrm{~mm}, 5 \mu \mathrm{m}$, Dalian Elite Analytical Instruments Co., Ltd., Liaoning, China). 
Separation was conducted by isocratic mode with a $10 \mu \mathrm{L}$ of injection volume at room temperature. Before use, the mobile phase and sample solution must be degassed using an ultrasonic bath after passing through a $450 \mathrm{~nm}$ membrane filter (Aladdin, Shanghai, China).

The detection wavelength of geniposidic acid and geniposide was observed at $240 \mathrm{~nm}$. The flow rate was $1.0 \mathrm{~mL} / \mathrm{min}$. The system of methanol-water-glacial acetic acid $(25: 75: 1.5$, v/v/v) was used to separate geniposidic acid and geniposide. HPLC chromatograms achieved baseline separation of geniposidic acid and geniposide within $30 \mathrm{~min}$. The retention times of geniposidic acid and geniposide were 5.95 and $18.21 \mathrm{~min}$, respectively. Calibration curves of geniposidic acid and geniposide were $Y_{\text {Geniposidic acid }}=20147544 x+28491$ $\left(R^{2}=0.9996\right)$ and $Y_{\text {Geniposide }}=19948741 x-33505\left(R^{2}=\right.$ 0.9997). Good linearities were observed for each compound when the concentration varies from 0.02 to $0.5 \mathrm{mg} / \mathrm{mL}$, respectively.

The standards were accurately weighted and mixed with methanol to prepare stock solutions with a concentration of $0.5 \mathrm{mg} / \mathrm{mL}$. The stock solutions were stored at $4^{\circ} \mathrm{C}$ before HPLC analysis. The above solutions were diluted with methanol to construct calibration curves.

2.3. Pretreatment of E. ulmoides Bark. The lipid of E. ulmoides bark $(100.0 \mathrm{~g})$ was extracted by hot reflux extraction for $2 \mathrm{~h}$ in $1000 \mathrm{~mL}$ of petroleum ether. The mixture was filtered immediately when it is hot. The residue was extracted twice under the same conditions as described above. The degreased material was dried and used throughout.

2.4. IMSHE Procedure. For IMSHE, different ionic liquids were accurately weighed (molar mass) and mixed with deionized water to prepare ionic liquid aqueous solutions. Dried degreased sample powder was mixed with the above solutions in $25 \mathrm{~mL}$ flasks, respectively. Subsequently, the flasks were placed into microwave oven (Sineo Chemical Equipment Corp., Shanghai, China). The optimum anions and cations, concentration of ionic liquid, irradiation power and time, and dosage of solvent were studied by a series of single-factor tests. Each experiment was performed in triplicate.

2.5. Optimization of IMSHE by Response Surface Methodology (RSM). The three independent parameters, that is, irradiation power and time and the liquid-solid ratio optimized by Box-Behnken design (BBD), were carried out by DesignExpert 8.0.5 software. The range and level of the three factors which were used in the optimization study and the experimental design matrix are specified in Table 1.

\subsection{Separation of Geniposidic Acid}

2.6.1. Adsorbents. Macroporous resins including HPD80, HPD100B, D101, HPD722, DM130, HPD400A, HPD600, and HPD500 were purchased from Baoen Chemical Co., Ltd. (Hebei, China). Prior to the adsorption experiments, weighed amounts of macroporous resins were soaked in $80 \%$ ethanol and subsequently washed by deionized water thoroughly. The physical properties and moisture contents of macroporous resins were shown in Table 2.
2.6.2. Static Adsorption and Desorption Tests. The static adsorption tests of geniposidic acid were carried out as follows: $1.00 \mathrm{~g}$ absolute dry weight hydrated tested macroporous resins were put into flask with a lid, and then $10 \mathrm{~mL}$ hydrolysate of geniposide was added. The concentration of geniposidic acid was $0.23 \mu \mathrm{mol} / \mathrm{mL}$. The flasks were put into a water bath at $30^{\circ} \mathrm{C}$ for $24 \mathrm{~h} .1 \mathrm{~mL}$ hydrolysate was centrifuged prior to HPLC for determination of geniposidic acid.

After adsorption equilibrium was reached, the resins were first washed by deionized water and then desorbed with $10 \mathrm{~mL}$ $20 \%$ ethanol. The flask was shaken $(120 \mathrm{rpm})$ at a constant temperature of $25^{\circ} \mathrm{C}$ for $4 \mathrm{~h}$. The concentration of geniposidic acid in desorption solution was analyzed by HPLC.

2.7. SEM. After being dried, the sectioned particles of the materials treated with various processes were observed by an S-520 model scanning electron microscopy (Hitachi, San Jose, CA, USA) under high vacuum condition at $10 \mathrm{kV}$ (20 $\mu \mathrm{m}, 5000 \mathrm{x}$ magnification).

2.8. TG. Materials were weighed and then heated by a Thermogravimetric Analyzer (TGS-2, PerkinElmer, USA) with a heating rate of $5^{\circ} \mathrm{C} / \mathrm{min}$ using nitrogen flow $50 \mathrm{~mL} / \mathrm{min}$. The percentage weight loss of tested samples was measured from 50 to $800^{\circ} \mathrm{C}$.

2.9. Comparison of IMSHE with Reference Method. For IMSHE, experiments were performed under the optimal operating conditions obtained by RSM. For hot reflux simultaneous hydrolysis and extraction procedure (IHRSHE), $10.0 \mathrm{~g}$ dried sample was added into $150 \mathrm{~mL}$ of $0.4 \mathrm{~mol} / \mathrm{L}$ of [C6mim] Im and then heated by an electric heating jacket at $450 \mathrm{~W}$ for $120 \mathrm{~min}$. Compared with traditional microwave irradiation extraction (MSHE) and hot reflux extraction (HRSHE), $0.4 \mathrm{~mol} / \mathrm{L} \mathrm{NaOH}$ takes the place of the $0.4 \mathrm{~mol} / \mathrm{L}$ of [C6mim]Im as solvent to hydrolyze the geniposide, and other conditions were the same as IMSHE and IHRSHE.

2.10. Statistical Analysis. One-way analysis was used for analyzing the significant differences in all experimental results. All data were the average of three parallel measurements, which were expressed as the yield means \pm standard deviation.

\section{Results and Discussion}

\subsection{Screening of Basic Ionic Liquid}

3.1.1. Effect of Anion. Previous studies have demonstrated the influence of the structure of ionic liquid on their physical and chemical characteristics $[29,30]$, which affect the reaction or extraction efficiency. Recently researches have reported the application of ionic liquid on the hydrolysis of microcrystalline cellulose and the synthesis of biodiesel [31,32]. To evaluate the extracting capability and the hydrolytic ability of geniposide from E. ulmoides bark, the ionic liquids with different methylimidazolium cations and anions were studied in this paper. 
TABLE 1: Experimental design matrix to screen for variables that determine the yield of geniposidic acid and ANOVA results ${ }^{\mathrm{a}}$.

(a)

\begin{tabular}{lcccc}
\hline \multirow{2}{*}{ Run } & \multicolumn{4}{c}{ BBD experiments } \\
& $X_{1}{ }^{\mathrm{b}}$ & $X_{2}$ & $X_{3}$ & $Y$ \\
\hline 1 & $15(0)$ & $15(-1)$ & $540(+1)$ & 2.98 \\
2 & $15(0)$ & $15(-1)$ & $230(-1)$ & 2.58 \\
3 & $15(0)$ & $25(+1)$ & $230(-1)$ & 2.87 \\
4 & $20(+1)$ & $25(+1)$ & $385(0)$ & 3.30 \\
5 & $10(-1)$ & $25(+1)$ & $385(0)$ & 3.02 \\
6 & $20(+1)$ & $20(0)$ & $230(-1)$ & 2.72 \\
7 & $20(+1)$ & $15(-1)$ & $385(0)$ & 3.48 \\
8 & $20(+1)$ & $20(0)$ & $540(+1)$ & 2.85 \\
9 & $10(-1)$ & $15(-1)$ & $385(0)$ & 2.82 \\
10 & $15(0)$ & $20(0)$ & $385(0)$ & 3.30 \\
11 & $10(-1)$ & $20(0)$ & $540(+1)$ & 2.63 \\
12 & $15(0)$ & $20(0)$ & $385(0)$ & 3.25 \\
13 & $15(0)$ & $20(0)$ & $385(0)$ & 3.12 \\
14 & $15(0)$ & $20(0)$ & $385(0)$ & 3.15 \\
15 & $15(0)$ & $20(0)$ & $385(0)$ & 3.22 \\
16 & $15(0)$ & $25(+1)$ & $540(+1)$ & 2.68 \\
17 & $10(-1)$ & $20(0)$ & $230(-1)$ & 2.34 \\
\hline
\end{tabular}

(b)

\begin{tabular}{|c|c|c|c|c|c|}
\hline \multicolumn{6}{|c|}{ ANOVA } \\
\hline Source & Sum of squares & Degree of freedom & Mean square & $F$-value & $P$ value \\
\hline Model & 1.49 & 9 & 0.17 & 28.49 & $0.0001^{\mathrm{c}}$ \\
\hline$X_{1}$ & 0.30 & 1 & 0.30 & 51.43 & $0.0002^{\mathrm{c}}$ \\
\hline$X_{2}$ & $3.5 \times 10^{-6}$ & 1 & $3.5 \times 10^{-6}$ & $6.1 \times 10^{-4}$ & 0.9810 \\
\hline$X_{3}$ & 0.050 & 1 & 0.050 & 8.68 & $0.0215^{\mathrm{c}}$ \\
\hline$X_{1} X_{2}$ & 0.036 & 1 & 0.036 & 6.17 & $0.0420^{\mathrm{c}}$ \\
\hline$X_{1} X_{3}$ & $7.7 \times 10^{-3}$ & 1 & $7.7 \times 10^{-3}$ & 1.33 & 0.2874 \\
\hline$X_{2} X_{3}$ & 0.085 & 1 & 0.085 & 14.67 & $0.0065^{\mathrm{c}}$ \\
\hline$X_{1}^{2}$ & 0.040 & 1 & 0.040 & 6.85 & $0.0346^{\mathrm{c}}$ \\
\hline$X_{2}^{2}$ & $8.4 \times 10^{-3}$ & 1 & $8.4 \times 10^{-3}$ & 1.45 & 0.2673 \\
\hline$X_{3}^{2}$ & 0.95 & 1 & 0.95 & 163.18 & $<0.0001^{\mathrm{c}}$ \\
\hline Residual & 0.041 & 7 & $5.8 \times 10^{-3}$ & & \\
\hline Lack of fit & 0.020 & 3 & $6.6 \times 10^{-3}$ & 1.28 & 0.3942 \\
\hline Pure error & 0.021 & 4 & $5.2 \times 10^{-3}$ & & \\
\hline Cor total & 1.53 & 16 & & & \\
\hline \multicolumn{6}{|c|}{ Credibility analysis of the regression equations } \\
\hline Standard deviation & Mean & Coefficient of variation $\%$ & $R^{2}$ & Adjusted $R^{2}$ & $\begin{array}{l}\text { Adequacy } \\
\text { precision }\end{array}$ \\
\hline 0.08 & 2.96 & 2.57 & 0.9734 & 0.9393 & 19.23 \\
\hline
\end{tabular}

${ }^{\mathrm{a}}$ The results were obtained with Design-Expert 7.0 software.

${ }^{\mathrm{b}} X_{1}$ is the microwave irradiation time (min), $X_{2}$ is the liquid-solid ratio $(\mathrm{mL} / \mathrm{g}), X_{3}$ is the microwave irradiation power $(\mathrm{W})$, and $Y$ is the yield of geniposidic acid $(\mu \mathrm{mol} / \mathrm{g})$.

${ }^{c}$ Significant at $P<0.05$.

Chen et al. [26] reported that the anion of ionic liquid can influence $\mathrm{pKb}$ value and thus influences catalytic properties. The 1-butyl-3-methylimidazolium with three different anions $\left(\mathrm{Im}^{-}, \mathrm{OAc}^{-}\right.$, and $\left.\mathrm{OH}^{-}\right)$, therefore, was investigated.
Samples $(0.5 \mathrm{~g})$ were added into $10 \mathrm{~mL}$ different ionic liquid solutions with the same concentration of $0.2 \mathrm{~mol} / \mathrm{L}$. The mixtures were irradiated at $385 \mathrm{~W}$ for $10 \mathrm{~min}$. As shown in Figure 2(a), different anions significantly influenced the 
TABLE 2: Adsorbing capacity and desorption ratio of the test macroporous resins.

\begin{tabular}{lccccc}
\hline Trade name & Polarity & Surface area $\left(\mathrm{m}^{2} / \mathrm{g}\right)$ & Moisture contents $(\%)$ & Adsorbing capacity $(\mu \mathrm{mol} / \mathrm{g})$ & Desorption ratio $(\%)$ \\
\hline HPD80 & Nonpolar & $350-400$ & 67.97 & 0.82 & 93.25 \\
HPD100B & Nonpolar & $500-580$ & 66.89 & 6.93 & 89.57 \\
D101 & Weak-polar & $400-600$ & 66.76 & 1.18 & 56.36 \\
HPD722 & Weak-polar & $485-530$ & 73.55 & 1.33 & 48.96 \\
DM130 & Middle-polar & $500-550$ & 64.32 & 1.98 & 91.23 \\
HPD400A & Middle-polar & $500-550$ & 65.99 & 2.09 & 78.36 \\
HPD600 & Polar & $550-600$ & 58.97 & 1.46 & 65.12 \\
HPD500 & Polar & $500-550$ & 65.63 & 1.25 & 71.53 \\
\hline
\end{tabular}

IMSHE process. The yield of geniposidic acid treated with [C6mim] Im was $2.8 \pm 0.11 \mu \mathrm{mol} / \mathrm{g}$ which was much higher than those treated with [C6mim] OH and [C6mim]OAc. Basic imidazolide ionic liquid can hydrolyze cellulose and hemicellulose and dissolve lignin of bark. Therefore, the basic imidazolide ionic liquid not only can hydrolyze geniposide, but also can hydrolyze the cellulose and hemicellulose of cell wall. Before hydrolysis of geniposide, the cell wall was destroyed by basic imidazolide ionic liquid firstly. This could accelerate release and dissolution of geniposide, which can also improve the hydrolysis rate of geniposide efficiently. These results indicated that $[\mathrm{C} 6 \mathrm{mim}] \mathrm{Im}$ was more efficient than $[\mathrm{C} 6 \mathrm{mim}] \mathrm{OAc}$ and $[\mathrm{C} 6 \mathrm{mim}] \mathrm{OH}$ for hydrolyzing geniposide into geniposidic acid. Similar results were obtained in the catalyzing Knoevenagel condensation reaction [26].

3.1.2. Effect of the Alkyl Chain Length. Paduszyński et al. [33] reported the effect of cation functionalization on thermophysical properties of ionic liquids. To gain high conversion rate of geniposide and better yield of geniposidic acid, five ionic liquids with the same anion of $\mathrm{Im}^{-}$and different cations $\left([\mathrm{C} 2 \mathrm{mim}]^{+},[\mathrm{C} 4 \mathrm{mim}]^{+},[\mathrm{C} 6 \mathrm{mim}]^{+},[\mathrm{C} 8 \mathrm{mim}]^{+}\right.$, and $\left.[\mathrm{C} 10 \mathrm{mim}]^{+}\right)$were applied to investigate the impacts of different alkyl on the properties of ionic liquid. Samples $(0.5 \mathrm{~g})$ were added into $10 \mathrm{~mL}$ different ionic liquid solutions with the same concentration of $0.2 \mathrm{~mol} / \mathrm{L}$. The mixtures were irradiated at $385 \mathrm{~W}$ for $10 \mathrm{~min}$. Figure 2(a) showed that the yield of geniposidic acid was increased up to $2.80 \pm 0.11 \mu \mathrm{mol} / \mathrm{g}$ when alkyl changed from ethyl to hexyl. However, the yield of geniposidic acid decreased obviously from $2.80 \pm 0.11$ to $1.35 \pm 0.06 \mu \mathrm{mol} / \mathrm{g}$ as alkyl chain length increased to decyl. According to the results of comparison experiments, the [C6mim] Im was selected as the optimal catalyst for preparing geniposidic acid in subsequent optimization studies.

3.1.3. Effect of Ionic Liquid Concentration. The same mass of samples as above was added into $10 \mathrm{~mL}$ of [C6mim] Im solution with different concentrations $(0.1,0.2,0.3,0.4$, and $0.5 \mathrm{~mol} / \mathrm{L}$ ) for the purpose of studying the effects of different concentration of $[\mathrm{C} 6 \mathrm{mim}] \mathrm{Im}$ on the IMSHE process. The mixtures were irradiated at $385 \mathrm{~W}$ for $10 \mathrm{~min}$. Figure 2(b) presented that the yield of the geniposidic acid was changed from $2.14 \pm 0.11$ to $2.86 \pm 0.14 \mu \mathrm{mol} / \mathrm{g}$ when the concentration of [C6mim] Im varied from 0.1 to $0.2 \mathrm{~mol} / \mathrm{L}$. The yield of geniposidic acid reached its maximum at the concentration of $0.4 \mathrm{~mol} / \mathrm{L}$. When further increasing [C6mim]Im concentration, the yield of geniposidic acid changed slightly. This may be because greater [C6mim] Im concentration leads to the greater solubility capacity and stronger alkalinity which could help to break down ester bond of geniposide to form easily carboxy group in alkali solution. Considering the above results, $0.4 \mathrm{~mol} / \mathrm{L}[\mathrm{C} 6 \mathrm{mim}] \mathrm{Im}$ was chosen as the suitable concentration for the subsequent experiments.

\subsection{Optimization of the IMSHE Process by Single-Factor Tests}

3.2.1. Effect of Microwave Power and Time. According to previous study [34], the microwave irradiation power was one of the most important factors on account of the fact that the microwave energy might influence the molecular interactions between the solvent and the targeted compounds significantly. Samples $(0.5 \mathrm{~g})$ were added into $10 \mathrm{~mL}$ of $0.4 \mathrm{~mol} / \mathrm{L}$ [C6mim] Im aqueous solutions. The mixtures were irradiated at different power $(120,230,385,540$, and $700 \mathrm{~W}$ ) for $10 \mathrm{~min}$. In the light of Figure 3(a), the yield of geniposidic acid changed obviously from $1.40 \pm 0.06$ to $2.81 \pm$ $0.11 \mu \mathrm{mol} / \mathrm{g}$ when the microwave heating power changed from 120 to $385 \mathrm{~W}$. But, geniposidic acid yield decreased to $2.61 \pm 0.10 \mu \mathrm{mol} / \mathrm{g}$ when further increasing the power up to $700 \mathrm{~W}$. High microwave irradiation power does not result in high yield of geniposidic acid. This is maybe due to the fact that high irradiation power leads to partial carbonization of samples as internal overheating and the isomerization or degradation of geniposidic acid. This result is similar to those reported by Yao et al. [35] and Liu et al. [23]. Hence, 230$540 \mathrm{~W}$ was taken for BBD optimization.

In order to choose optimal treatment time, tests were performed at $385 \mathrm{~W}$ for different durations $(5,10,15,20,25$, and $30 \mathrm{~min}$ ). In the light of Figure 3(b), yield of geniposidic acid increased relatively rapidly when the treatment time varied from 5 to $10 \mathrm{~min}$. The yield reached higher values of $3.01 \pm 0.12 \mu \mathrm{mol} / \mathrm{g}$ at $20 \mathrm{~min}$, and then the yield of geniposidic acid changed little when further prolonging the treatment time. Thus, 10-20 min was selected for BBD optimization.

3.2.2. Effect of Liquid-Solid Ratio. Experiments were performed by different liquid-solid ratio. Samples $(0.5 \mathrm{~g})$ were added into different volume $(5,10,12.5,15$, and $20 \mathrm{~mL})$ of $0.4 \mathrm{~mol} / \mathrm{L}$ [C6mim] Im solutions. The mixtures were irradiated in the microwave oven at $385 \mathrm{~W}$ for $10 \mathrm{~min}$. Figure 3(c) 


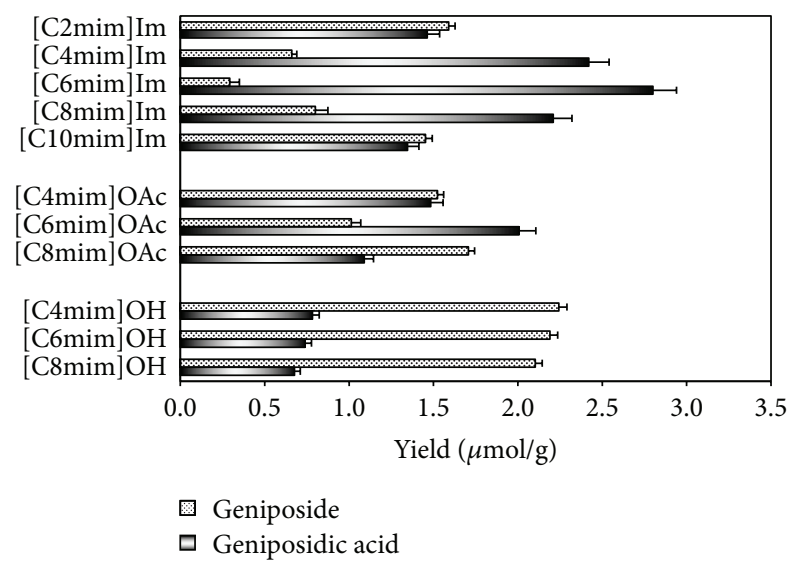

(a)

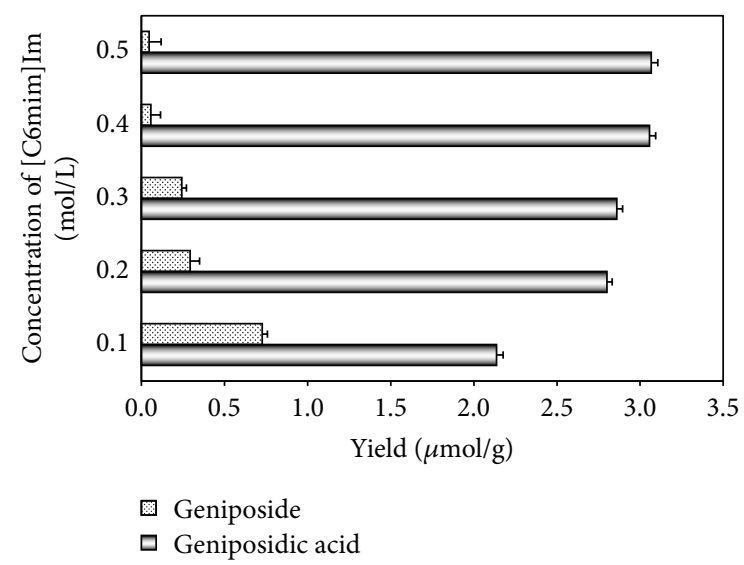

(b)

FIGURE 2: Effects of different ionic liquids (a) and their concentration (b) on the yield of geniposidic acid from E. ulmoides bark.

illustrated that the geniposidic acid yield increased significantly from $1.89 \pm 0.10$ to $2.82 \pm 0.14 \mu \mathrm{mol} / \mathrm{g}$ when the volume of solution varied from 5 to $10 \mathrm{~mL}$. When continuing to increase the liquid-solid ratio, the increase of geniposidic acid yield was not significant. In view of saving in material and solvent, a liquid-solid ratio of $15 \mathrm{~mL} / \mathrm{g}$ to $25 \mathrm{~mL} / \mathrm{g}$ was selected for BBD optimization.

3.3. Optimization Parameters by BBD. According to the results of single-factor experiments, the $\mathrm{BBD}$ was used to further evaluate the interactions between the factors including irradiation power and time and liquid-solid ratio. Table 1 illustrated that the model is significant because the $F$-value was 28.49 . There is only a $0.01 \%$ chance that occurred because of noise. Values of "Prob $>F$ " $\left(X_{1}, X_{3}, X_{1} X_{2}, X_{2} X_{3}, X_{1}^{2}\right.$, and $X_{3}^{2}$ ) less than 0.0500 demonstrated that these factors are significant. The model terms of $X_{2}$ and $X_{2}{ }^{2}$ are indistinctive because they were greater than 0.1000 . The "lack of fit $F$ value" of 1.28 indicates that the "lack of fit" is indistinctive compared with the pure error, which is desirable. The "lack of fit $F$-value" of $39.42 \%$ could occur because of noise. Value of "adequacy precision" was 19.23 which was satisfactory and demonstrated that the model was better enough to navigate the design space.

The three-dimensional response surface plots for the mutual effect of single factors on yield of geniposidic acid were shown in Figure 4. Figure 4(a) presents the interaction of different treatment time (min) and liquid-solid ratio $(\mathrm{mL} / \mathrm{g})$ with the same power. The yield of geniposidic acid was increased significantly when prolonging the duration of microwave treatment. The yield changed gradually as the liquid-solid ratio ( $\mathrm{mL} / \mathrm{g}$ ) varied from 15 to $25 \mathrm{~mL} / \mathrm{g}$. Figure 4(b) showed the surface plot at different treatment time (min) and power (W) with the same liquid-solid ratio. The yield of geniposidic acid changed little when prolonging the duration. However, the yield increased significantly when the irradiation power changed from 230 to $385 \mathrm{~W}$ and subsequently decreased dramatically when further increasing power. Figure 4(c) showed the surface plot at different irradiation power (W) and liquid-solid ratio $(\mathrm{mL} / \mathrm{g})$ with a stable treatment time. The yield significantly increased when the power varied from 230 to $385 \mathrm{~W}$ and then decreased obviously from 385 to $540 \mathrm{~W}$. This indicated that the irradiation power is more important than liquid-solid ratio for preparation of geniposidic acid. The optimized conditions given by BBD software were as follows: 20 min of treatment time, $415 \mathrm{~W}$ of irradiation power, and $15 \mathrm{~mL} / \mathrm{g}$ of liquid-solid ratio. Under these conditions of point prediction, the total yield was $3.5 \mu \mathrm{mol} / \mathrm{g}$.

The verification tests were performed three times under these optimized conditions given by BBD software $(20 \mathrm{~min}$ of treatment time, $415 \mathrm{~W}$ of irradiation power, and $15 \mathrm{~mL} / \mathrm{g}$ of liquid-solid ratio). The actual yield reached $3.41 \pm$ $0.17 \mu \mathrm{mol} / \mathrm{g}$.

\subsection{Preliminary Separation of Geniposidic Acid Using Macro-} porous Resin. The adsorption capacity and desorption ratio of geniposidic acid on the eight types of resins are depicted in Table 2. In the light of Table 2, the adsorption capacity of geniposidic acid on DM130 and HPD400A macroporous resin was higher than those of other resins. But the desorption ratio of geniposidic acid on DM130 was significantly higher than that of HPD400A $(P<0.05)$, which could be attributed to their similarity to the polarity of geniposidic acid. The adsorption capacity of macroporous resins is related to the polarity and the chemical features of the adsorbed substance. Macroporous resins with middle polarity exhibited stronger adsorption abilities to polar substances. The selection of proper macroporous resins should be in accordance with the resins polarities, adsorption capacity, and desorption ratios. The middle-polar macroporous resin DM130 has shown better adsorption capacity and desorption ratio because of its similar polarity with the polar substance geniposidic acid. Hence, DM130 resin was selected to separate the geniposidic acid from the hydrolysate of geniposide.

3.5. General Morphology Changes after Treatment with Different Processes. To explain the structural alteration and the 


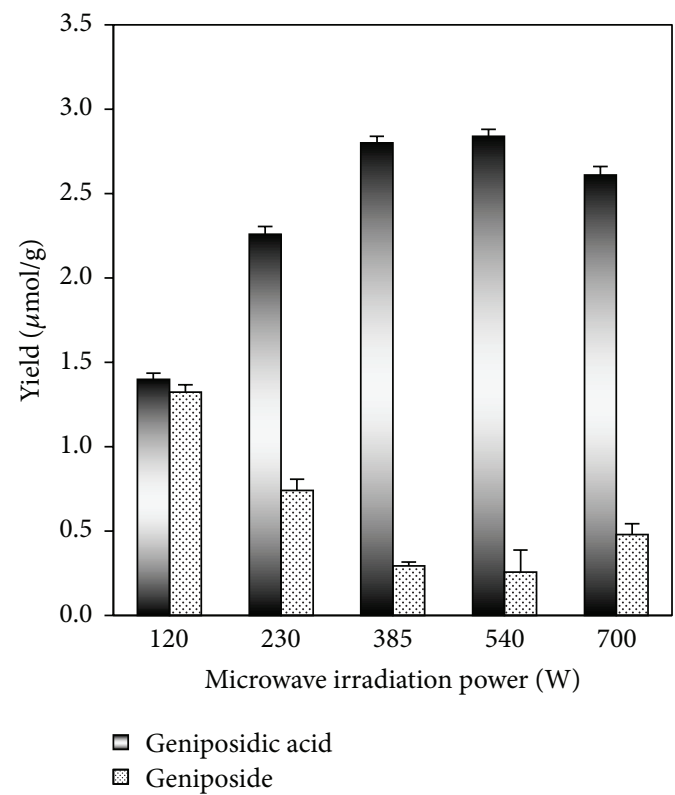

(a)

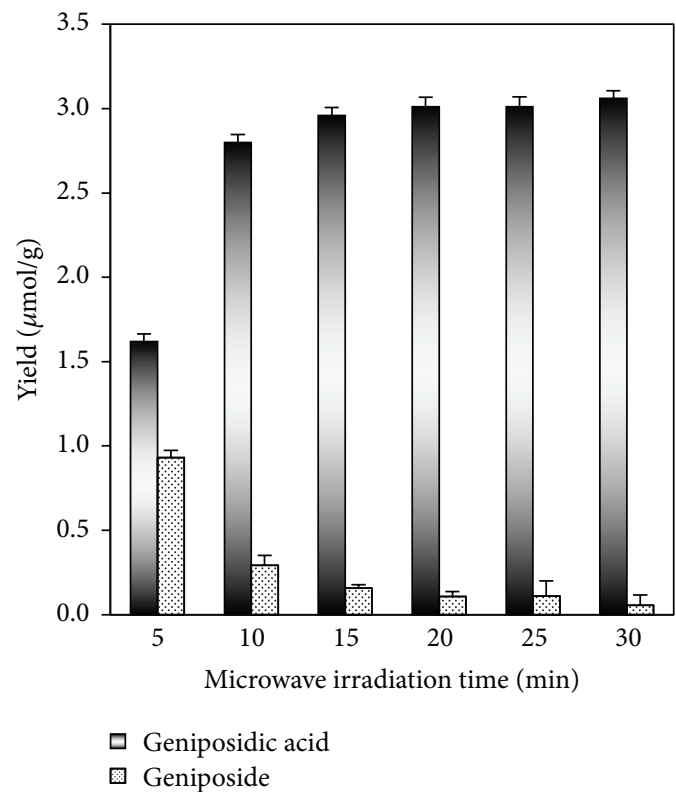

(b)

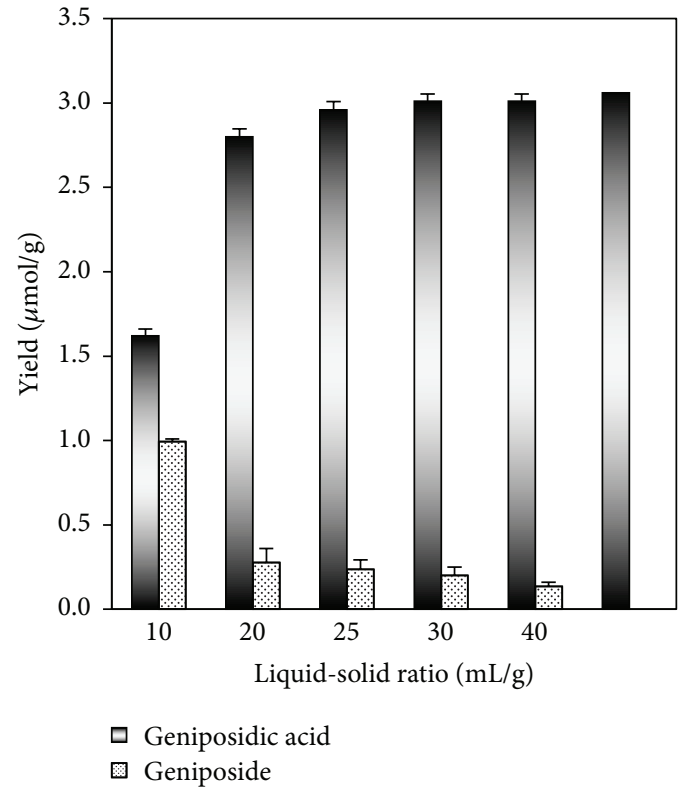

(c)

FIGURE 3: Effects of microwave irradiation power (a), microwave irradiation time (b), and liquid-solid ratio (c) on the yield of geniposidic acid.

mechanism of hydrolysis and extraction during the IMSHE processes, the plant materials with different treatment were analyzed by SEM and TG.

3.5.1. SEM Analysis of Materials. To observe the surface morphology, samples obtained by different processes were determined by SEM. Figure 5 showed the surface morphology of E. ulmoides bark without treatment (a) and after degreasing (b), microwave-assisted water treatment (c), and IMSHE treatment (d), respectively. It can be seen that different extraction procedures produce distinguishable surface morphology changes. The morphological structures represent ordered tracheary cells of the xylem and the surface of the raw material covered with amount of curved filaments (Figure 5(a)). It can be seen that there are few of curved filaments on the surface of degreased material (Figure 5(b)). Compared to raw material, the surface of cells in degreasing sample was almost not changed. After microwave-assisted water treatment (Figure 5(c)), the cell walls had a partial destruction or no destruction leading to some of active substances being still in plant cells. As expected, the plant 


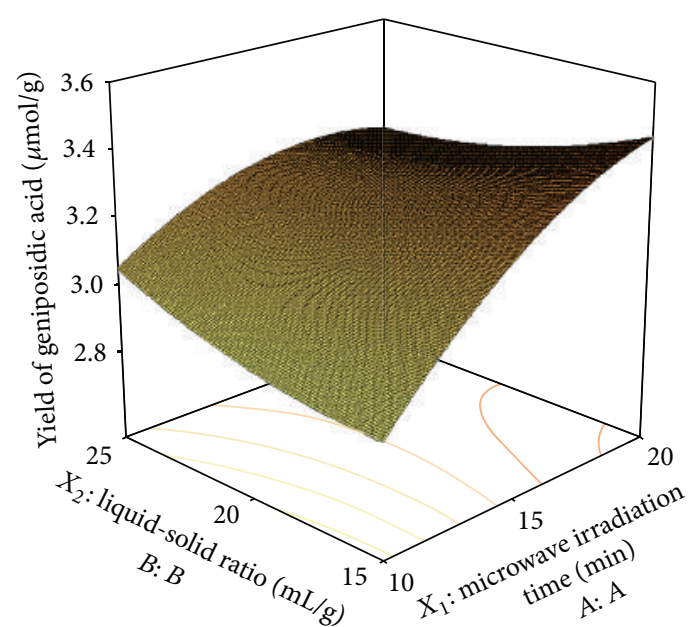

(a)

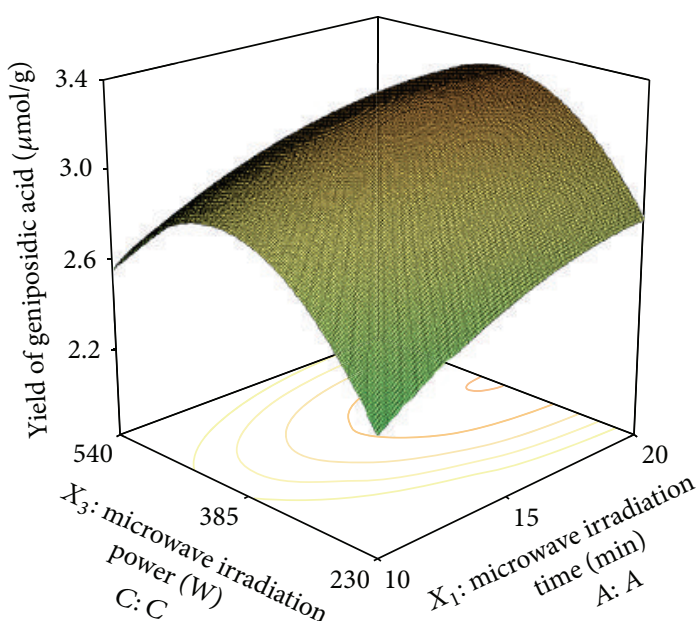

(b)

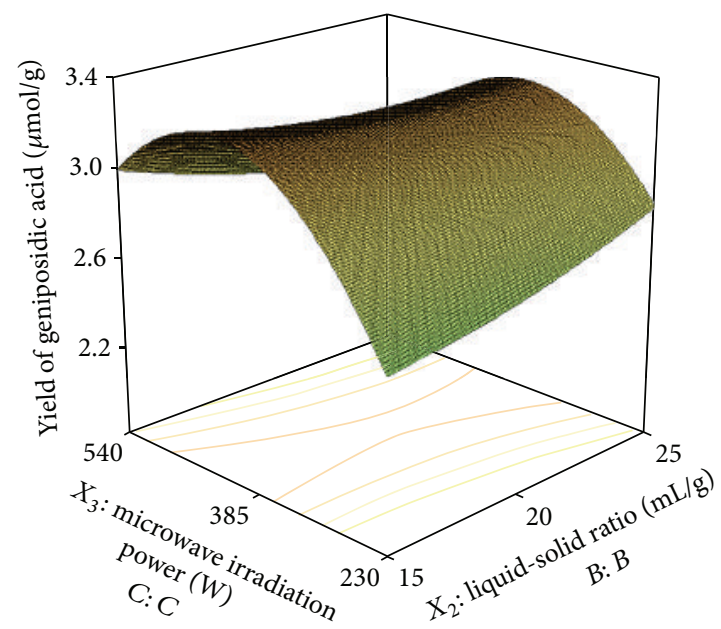

(c)

FIGURE 4: Three-dimensional response surface plots for the effect of independent variables on yield of geniposidic acid: (a) microwave irradiation time ( $\mathrm{min}$ ) and liquid-solid ratio $(\mathrm{mL} / \mathrm{g})$; (b) microwave irradiation time $(\mathrm{min})$ and microwave irradiation power $(\mathrm{W})$; (c) microwave irradiation power $(\mathrm{W})$ and liquid-solid ratio $(\mathrm{mL} / \mathrm{g})$.

cell walls were partly destroyed by IMSHE treatment; the cell walls became thinner and disorganised (Figure 5(d)), which resulted in the release of geniposide. This made the hydrolyzing of geniposide easier.

3.5.2. TG Analysis of Materials. In this part, the thermogravimetric degradation curves of the E. ulmoides bark processed were given in Figure 6 . The profile of the TG showed a weight loss between 50 and $800^{\circ} \mathrm{C}$. As shown in Figure 6(a, b, and c), raw material, degreased material, and microwave-assisted water treatment material lost more weight than that after IMSHE treatment (Figure 6(d)). It was further indicated that IMSHE is an efficient preparation method for geniposidic acid.

3.6. Preliminary Estimation of Cost, Energy, and Environment Ecology. Recently, low cost and energy consumption, high efficiency, and environmentally-friendly method are clearly advantageous for the preparation of the bioactive compounds from plant material. It can be seen from Table 3 that the electric consumption of IMSHE and MSHE is only $0.14 \mathrm{kWh}$ which is much lower than those of IHRSHE and HRSHE (0.90 kWh). With the similar geniposidic acid yield, IHRSHE and HRSHE required a more tedious duration (120 min) and higher power (450 W) compared with IMSHE and MSHE (20 min; $415 \mathrm{~W}$ ). The yield of geniposidic acid per kilowatt hour for IMSHE is $24.36 \pm 1.22 \mu \mathrm{mol} / \mathrm{g} \cdot \mathrm{kWh}$, which is obviously higher than those of MSHE (2.97 \pm $0.12 \mu \mathrm{mol} / \mathrm{g} \cdot \mathrm{kWh})$, IHRSHE $(3.02 \pm 0.11 \mu \mathrm{mol} / \mathrm{g} \cdot \mathrm{kWh})$, and HRSHE $(2.82 \pm 0.14 \mu \mathrm{mol} / \mathrm{g} \cdot \mathrm{kWh})$. Additionally, imidazolide basic ionic liquid is efficient for hydrolyzing geniposide compared to $\mathrm{NaOH}$. According to the literatures reported by $\mathrm{Ma}$ et al. [36] and Liu et al. [23], to produce $1 \mathrm{kWh}$ by combustion of fossil fuel (coal or fuel), it will reject $800 \mathrm{~g}$ of $\mathrm{CO}_{2}$ into the atmosphere. Therefore, $720.00 \mathrm{~g}$ of $\mathrm{CO}_{2}$ will 


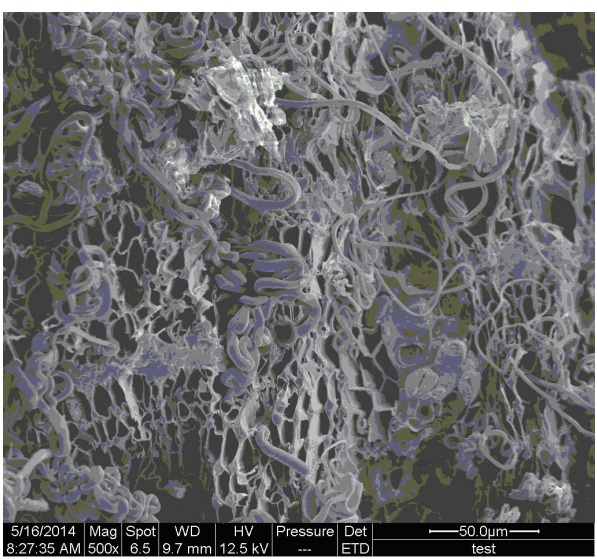

(a)

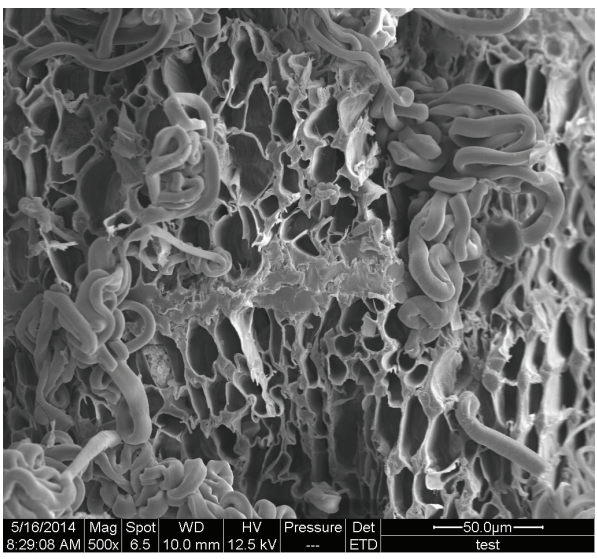

(c)

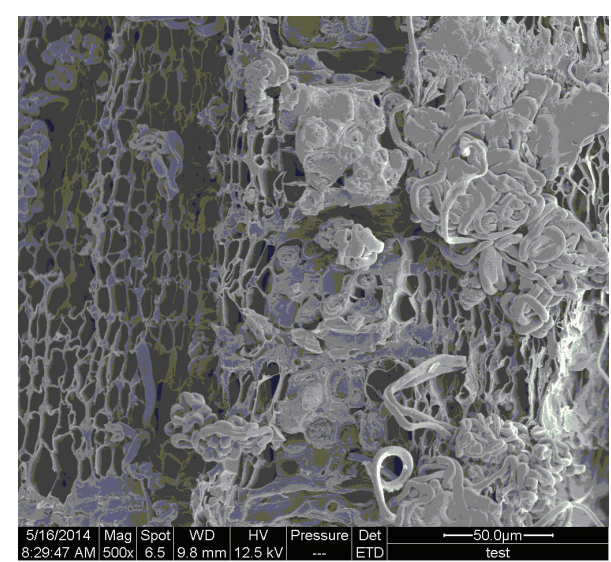

(b)

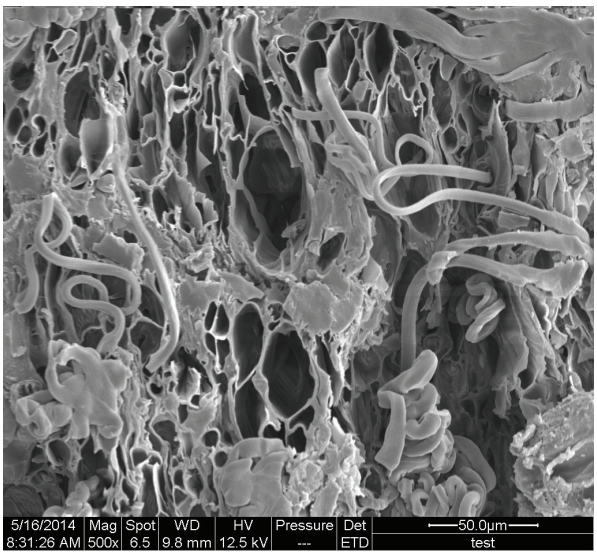

(d)

FIGURE 5: The SEM micrographs of raw material (a), degreased material (b), microwave-assisted water treatment material (c), and IMSHE treatment $(\mathrm{d})$.

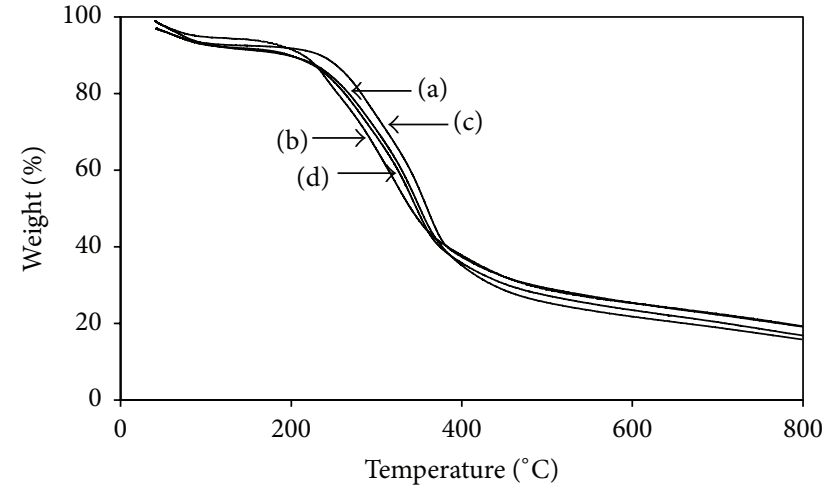

FIgURE 6: Thermogravimetric degradation curves of raw material (a), degreased material (b), microwave-assisted water treatment material (c), and IMSHE treatment (d).

be emitted into the atmosphere in the process of IHRSHE and HRSHE, which is 6.4-fold of those of IMSHE and MSHE (112.00 $\mathrm{g} \mathrm{CO}_{2}$ ). This result demonstrated that this is an environmentally-friendly technique for producing bioactive compounds.

\section{Conclusions}

In the present research, imidazolide basic ionic liquid-based microwave-assisted simultaneous hydrolysis and extraction method was specially designed and first applied for preparation of geniposidic acid from $E$. ulmoides bark. After a series of experiments, 1-hexyl-3-methylimidazolium imidazolium salt $([\mathrm{C} 6 \mathrm{mim}] \mathrm{Im})$ was chosen as the optimal basic ionic liquid. According to the results of single-factor optimization tests, the operational conditions of this novel method were optimized by the BBD. After hydrolysis of geniposide, geniposidic acid is separated by DM130 macroporous resin. For IMSHE, the yield of geniposidic acid reached $3.41 \pm$ $0.17 \mu \mathrm{mol} / \mathrm{g}$ within $20 \mathrm{~min}$, and for IHRSHE the yield of geniposidic acid was only $3.02 \pm 0.11 \mu \mathrm{mol} / \mathrm{g}$ within $120 \mathrm{~min}$. Additionally, SEM and TG result illustrated that the proposed technique in this paper could destroy plant cell walls efficiently which significantly increased the release of active 
TABLE 3: Comparison of economic effect and environmental impact with different methods, mean $\pm \operatorname{SD}(n=3)$.

\begin{tabular}{|c|c|c|c|c|}
\hline & IMSHE & MSHE & IHRSHE & HRSHE \\
\hline Solvent & {$[\mathrm{C} 6 \mathrm{mim}] \mathrm{Im}$} & $\mathrm{NaOH}$ & {$[\mathrm{C} 6 \mathrm{mim}] \mathrm{Im}$} & $\mathrm{NaOH}$ \\
\hline Electric power $(\mathrm{W})$ & \multicolumn{2}{|c|}{415} & \multicolumn{2}{|c|}{450} \\
\hline Electric consumption time (min) & \multicolumn{2}{|c|}{20} & \multicolumn{2}{|c|}{120} \\
\hline Electric consumption $(\mathrm{kWh})$ & \multicolumn{2}{|c|}{0.14} & \multicolumn{2}{|c|}{0.90} \\
\hline Environmental impact $\left(\mathrm{CO}_{2}\right.$ emission load, $\left.\mathrm{g}\right)$ & \multicolumn{2}{|c|}{112.00} & \multicolumn{2}{|c|}{720.00} \\
\hline Yield of geniposidic acid $(\mu \mathrm{mol} / \mathrm{g})$ & $3.41 \pm 0.17$ & $2.97 \pm 0.12$ & $3.02 \pm 0.11$ & $2.82 \pm 0.14$ \\
\hline Yield of geniposidic acid per kilowatt hour $(\mu \mathrm{mol} / \mathrm{g} \cdot \mathrm{kWh})$ & $24.36 \pm 1.22$ & $20.77 \pm 1.04$ & $3.36 \pm 0.168$ & $3.13 \pm 0.16$ \\
\hline
\end{tabular}

substance. Thus, this is a novel technique for preparation of geniposidic acid from E. ulmoides bark.

\section{Competing Interests}

The authors declare that they have no competing interests.

\section{Acknowledgments}

The authors gratefully acknowledge the financial supports by the State Key Laboratory of Tree Genetics and Breeding (Northeast Forestry University, 201105).

\section{References}

[1] G. W. Lee, H. C. Yoon, and S. Y. Byun, "Inhibitory effect of Eucommia ulmoides Oliver on adipogenic differentiation through proteome analysis," Enzyme and Microbial Technology, vol. 35, no. 6-7, pp. 632-638, 2004.

[2] L.-F. Luo, W.-H. Wu, Y.-J. Zhou, J. Yan, G.-P. Yang, and D.S. Ouyang, "Antihypertensive effect of Eucommia ulmoides Oliv. extracts in spontaneously hypertensive rats," Journal of Ethnopharmacology, vol. 129, no. 2, pp. 238-243, 2010.

[3] Z. Xian, J.-P. Cai, Y.-H. Zhang, and X.-L. Tan, "Expression of osteogenesis- and adipogenesis-related transcription factors during osteogenic differentiation of rat mesenchymal stem cells induced by eucommia bark," Journal of Clinical Rehabilitative Tissue Engineering Research, vol. 14, no. 19, pp. 3523-3526, 2010.

[4] J. N. Ho, Y. H. Lee, J. S. Park et al., "Protective effects of aucubin isolated from Eucommia ulmoides against UVB-induced oxidative stress in human skin fibroblasts," Biological and Pharmaceutical Bulletin, vol. 28, no. 7, pp. 1244-1248, 2005.

[5] Z. Jia, W. Huang, and A. Xue, "Flavonoids extraction technology from Eucommia ulmoides leaves and the measurement of antioxidant and red blood cell protecting properties," Food Research and Development, vol. 29, no. 5, pp. 46-49, 2008.

[6] C.-Y. Kwan, C.-X. Chen, T. Deyama, and S. Nishibe, "Endothelium-dependent vasorelaxant effects of the aqueous extracts of the Eucommia ulmoides Oliv. leaf and bark: implications on their antihypertensive action," Vascular Pharmacology, vol. 40, no. 5, pp. 229-235, 2003.

[7] X. Jin, Y. Otonashi-Satoh, P. Sun et al., "Endothelium-derived hyperpolarizing factor (EDHF) mediates endothelium-dependent vasodilator effects of aqueous extracts from Eucommia ulmoides oliv. leaves in rat mesenteric resistance arteries," Acta Medica Okayama, vol. 62, no. 5, pp. 319-325, 2008.

[8] C.-Y. Kwan, W.-B. Zhang, T. Deyama, and S. Nishibe, "Endothelium-dependent vascular relaxation induced by Eucommia ulmoides Oliv. bark extract is mediated by NO and EDHF in small vessels," Naunyn-Schmiedeberg's Archives of Pharmacology, vol. 369, no. 2, pp. 206-211, 2004.

[9] S.-J. Kim, K.-M. Kim, J. Park, J.-H. Kwak, Y. S. Kim, and S.M. Lee, "Geniposidic acid protects against D-galactosamine and lipopolysaccharide-induced hepatic failure in mice," Journal of Ethnopharmacology, vol. 146, no. 1, pp. 271-277, 2013.

[10] H.-Y. Hsu, J.-J. Yang, S.-Y. Lin, and C.-C. Lin, “Comparisons of geniposidic acid and geniposide on antitumor and radioprotection after sublethal irradiation," Cancer Letters, vol. 113, no. 1-2, pp. 31-37, 1997.

[11] S. D. Wu, X. Y. Jiang, Q. Y. Chen, and X. Q. Chen, "Comparison of techniques for the extraction of the hypotensive drugs geniposidic acid and geniposide from Eucommia Ulmoides," Journal of the Iranian Chemical Society, vol. 4, no. 2, pp. 205214, 2007

[12] Y. Gao, Z.-Y. Chen, X. Liang, C. Xie, and Y.-F. Chen, "Antiatherosclerotic effect of geniposidic acid in a rabbit model and related cellular mechanisms," Pharmaceutical Biology, vol. 53, no. 2, pp. 280-285, 2015.

[13] H. Liu, S. Zhang, and Z.-H. Liu, "Simultaneous determination of geniposidic acid, chlorogenic acid, geniposide, and pinoresinol diglucoside in Eucommia ulmoides by HPLC," Chinese Traditional and Herbal Drugs, vol. 43, no. 8, pp. 1547-1549, 2012.

[14] J. Xie, Y. Zeng, H. Liang, H. Chen, and B. Tang, "Isolation and purification of geniposidic acid made from geniposide by hydrolyzing with alkali," Food Science and Technology, vol. 36, no. 11, pp. 226-229, 2011.

[15] J. Hoffmann, M. Nüchter, B. Ondruschka, and P. Wasserscheid, "Ionic liquids and their heating behaviour during microwave irradiation-a state of the art report and challenge to assessment," Green Chemistry, vol. 5, no. 3, pp. 296-299, 2003.

[16] J. L. Anderson, R. Ding, A. Ellern, and D. W. Armstrong, "Structure and properties of high stability geminal dicationic ionic liquids," Journal of the American Chemical Society, vol. 127, no. 2, pp. 593-604, 2005.

[17] F. van Rantwijk and R. A. Sheldon, "Biocatalysis in ionic liquids," Chemical Reviews, vol. 107, no. 6, pp. 2757-2785, 2007.

[18] F.-Y. Du, X.-H. Xiao, X.-J. Luo, and G.-K. Li, "Application of ionic liquids in the microwave-assisted extraction of polyphenolic compounds from medicinal plants," Talanta, vol. 78, no. 3, pp. 1177-1184, 2009.

[19] W. Ma, Y. Lu, R. Hu, J. Chen, Z. Zhang, and Y. Pan, "Application of ionic liquids based microwave-assisted extraction of three alkaloids $\mathrm{N}$-nornuciferine, O-nornuciferine, and nuciferine from lotus leaf," Talanta, vol. 80, no. 3, pp. 1292-1297, 2010.

[20] C.-H. Ma, T.-T. Liu, L. Yang, Y.-G. Zu, S.-Y. Wang, and R.-R. Zhang, "Study on ionic liquid-based ultrasonic-assisted extraction of biphenyl cyclooctene lignans from the fruit of Schisandra 
chinensis Baill," Analytica Chimica Acta, vol. 689, no. 1, pp. 110116, 2011.

[21] S. Zhu, Y. Wu, Q. Chen et al., "Dissolution of cellulose with ionic liquids and its application: a mini-review," Green Chemistry, vol. 8, no. 4, pp. 325-327, 2006.

[22] Y. Cao, J. Wu, J. Zhang, H. Li, Y. Zhang, and J. He, "Room temperature ionic liquids (RTILs): a new and versatile platform for cellulose processing and derivatization," Chemical Engineering Journal, vol. 147, no. 1, pp. 13-21, 2009.

[23] Z. Liu, Z. Chen, F. Han, X. Kang, H. Gu, and L. Yang, "Microwave-assisted method for simultaneous hydrolysis and extraction in obtaining ellagic acid, gallic acid and essential oil from Eucalyptus globulus leaves using Brönsted acidic ionic liquid $\left[\mathrm{HO}_{3} \mathrm{~S}\left(\mathrm{CH}_{2}\right)_{4} \mathrm{mim}\right] \mathrm{HSO}_{4}$," Industrial Crops and Products, vol. 81, pp. 152-161, 2016.

[24] F. Chen, X. Du, Y. Zu, and L. Yang, "A new approach for preparation of essential oil, followed by chlorogenic acid and hyperoside with microwave-assisted simultaneous distillation and dual extraction (MSDDE) from Vaccinium uliginosum leaves," Industrial Crops and Products, vol. 77, pp. 809-826, 2015.

[25] X. Chen, X. Li, H. Song, Y. Qian, and F. Wang, "Solvent-free aza-Markovnikov and aza-Michael additions promoted by a catalytic amount of imidazolide basic ionic liquids," Tetrahedron Letters, vol. 52, no. 28, pp. 3588-3591, 2011.

[26] X. Chen, X. Li, H. Song, Y. Lü, F. Wang, and A. Hu, "Synthesis of a basic imidazolide ionic liquid and its application in catalyzing Knoevenagel condensation," Chinese Journal of Catalysis, vol. 29, no. 10, pp. 957-959, 2008.

[27] M. Zawadzki, L. Niedzicki, W. Wieczorek, and U. Domańska, "Estimation of extraction properties of new imidazolide anion based ionic liquids on the basis of activity coefficient at infinite dilution measurements," Separation and Purification Technology, vol. 118, pp. 242-254, 2013.

[28] L. Chen, J. Chen, Z. Song et al., "Densities, viscosities, and excess properties of binary mixtures of two imidazolide anion functionalized ionic liquids with water at $\mathrm{T}=(293.15$ to 313.15$)$ K," The Journal of Chemical Thermodynamics, vol. 91, pp. 292300, 2015.

[29] T. Liu, X. Sui, R. Zhang et al., "Application of ionic liquids based microwave-assisted simultaneous extraction of carnosic acid, rosmarinic acid and essential oil from Rosmarinus officinalis," Journal of Chromatography A, vol. 1218, no. 47, pp. 8480-8489, 2011.

[30] L. Yang, L.-L. Li, T.-T. Liu et al., "Development of sample preparation method for isoliquiritigenin, liquiritin, and glycyrrhizic acid analysis in licorice by ionic liquids-ultrasound based extraction and high-performance liquid chromatography detection," Food Chemistry, vol. 138, no. 1, pp. 173-179, 2013.

[31] F. Parveen, T. Patra, and S. Upadhyayula, "Hydrolysis of microcrystalline cellulose using functionalized Bronsted acidic ionic liquids-a comparative study," Carbohydrate Polymers, vol. 135, pp. 280-284, 2016.

[32] P. Zhang, Y. Liu, M. Fan, and P. Jiang, "Catalytic performance of a novel amphiphilic alkaline ionic liquid for biodiesel production: influence of basicity and conductivity," Renewable Energy, vol. 86, pp. 99-105, 2016.

[33] K. Paduszyński, M. Okuniewski, and U. Domańska, “An effect of cation functionalization on thermophysical properties of ionic liquids and solubility of glucose in them-measurements and PC-SAFT calculations," The Journal of Chemical Thermodynamics, vol. 92, pp. 81-90, 2016.
[34] Q. Zhang, S.-H. Zhao, J. Chen, and L.-W. Zhang, "Application of ionic liquid-based microwave-assisted extraction of flavonoids from Scutellaria baicalensis Georgi," Journal of Chromatography B: Analytical Technologies in the Biomedical and Life Sciences, vol. 1002, Article ID 19583, pp. 411-417, 2015.

[35] H. Yao, X. Du, L. Yang et al., "Microwave-assisted method for simultaneous extraction and hydrolysis for determination of flavonol glycosides in Ginkgo foliage using Brönsted acidic ionic-liquid $\left[\mathrm{HO}_{3} \mathrm{~S}\left(\mathrm{CH}_{2}\right)_{4} \mathrm{mim}\right] \mathrm{HSO}_{4}$ aqueous solutions," International Journal of Molecular Sciences, vol. 13, no. 7, pp. 8775-8788, 2012.

[36] C.-H. Ma, L. Yang, Y.-G. Zu, and T.-T. Liu, "Optimization of conditions of solvent-free microwave extraction and study on antioxidant capacity of essential oil from Schisandra chinensis (Turcz.) Baill," Food Chemistry, vol. 134, no. 4, pp. 2532-2539, 2012. 


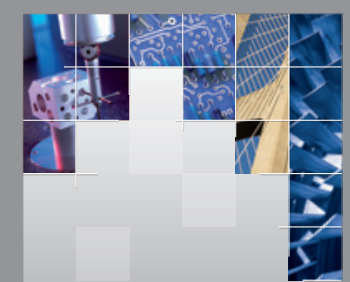

\section{Enfincering}
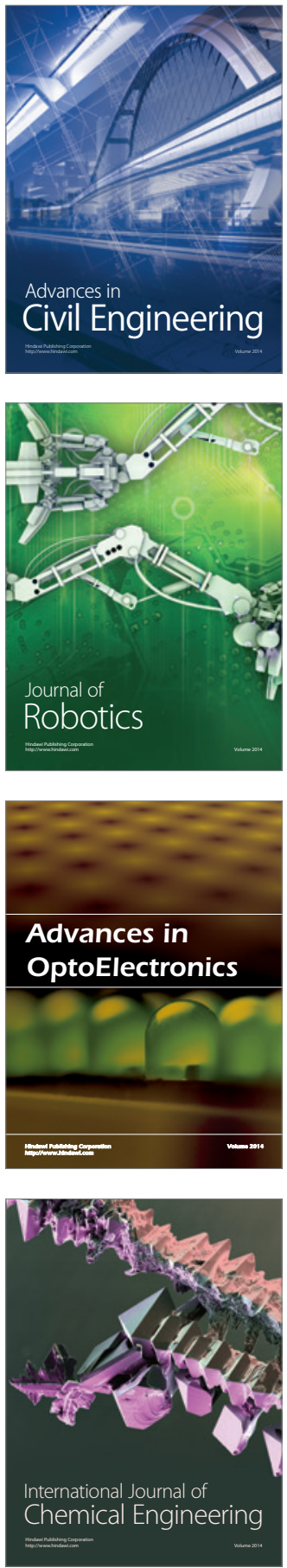

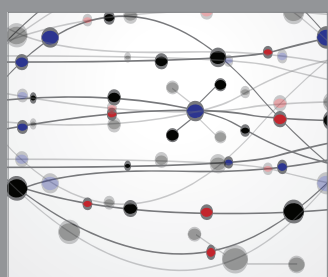

The Scientific World Journal

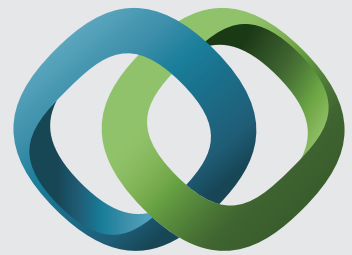

\section{Hindawi}

Submit your manuscripts at

http://www.hindawi.com
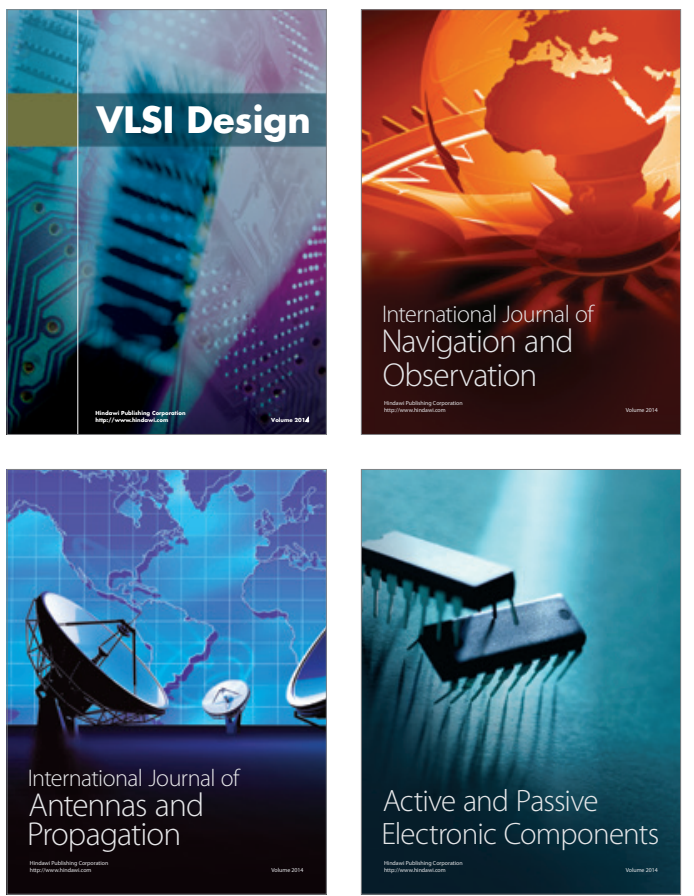
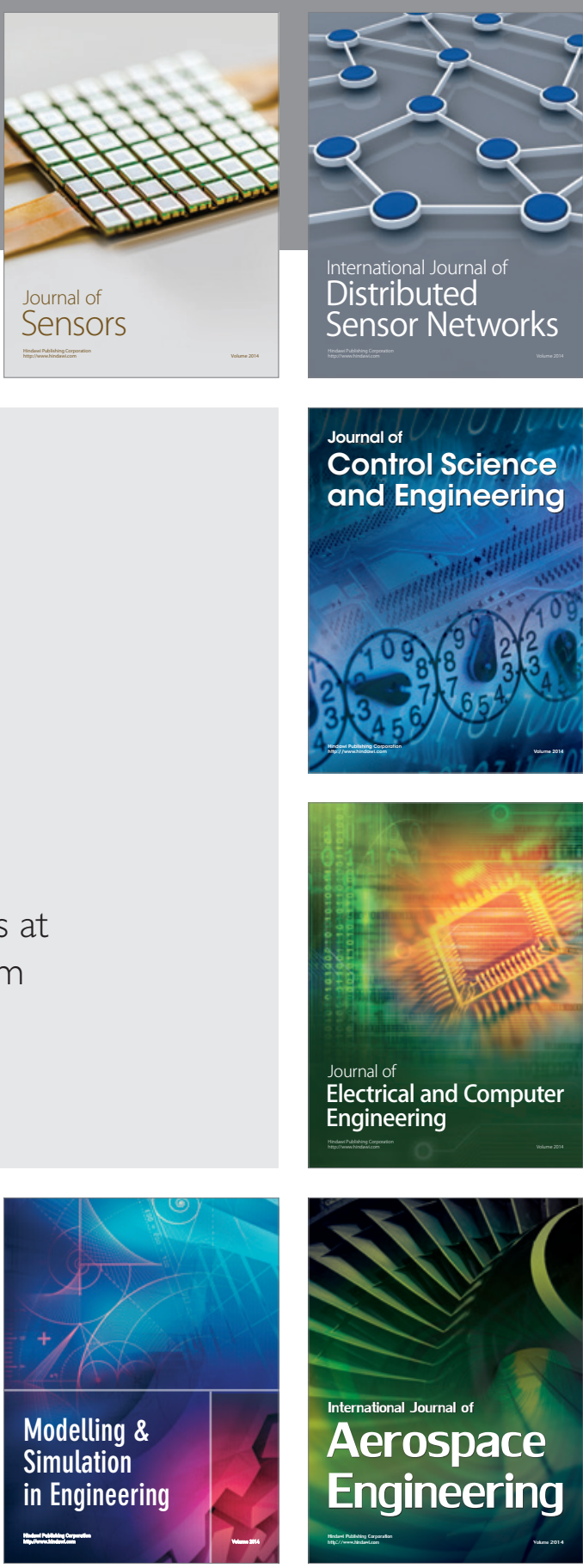

International Journal of

Distributed

Sensor Networks

Journal of

Control Science

and Engineering
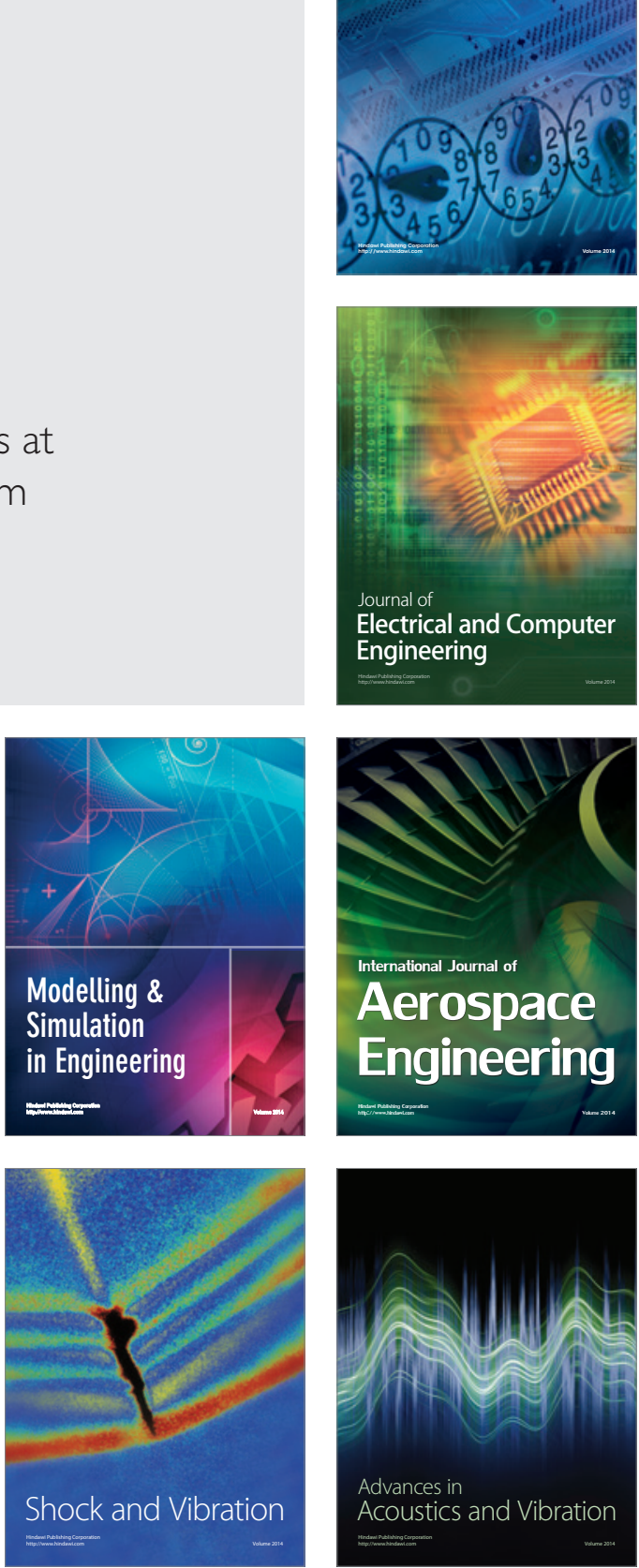